\title{
Monitoring dan Evaluasi Perkuliahan di Jurusan Fisika Universitas Negeri Malang
}

\author{
${ }^{1}$ Muhammad Reyza Arief Taqwa ${ }^{2}$ Atsnaita Yasrina, ${ }^{3}$ Alif Darmawan, \\ ${ }^{4}$ Fatah Kurniawan, ${ }^{5}$ Risky Putra Pramudia \\ 1,2,3.4,5 Jurusan Fisika, Universitas Negeri Malang, Indonesia
}
Email: ${ }^{1}$ reyza.arief.fmipa@um.ac.id, ${ }^{2}$ atsnaita.yasrina.fmipa@um.ac.id, 3darmawanalif.1703216@students.um.ac.id, ${ }^{4}$ kurniawan.1703216@students.um.ac.id, 5risky.putra.1703216@students.um.ac.id

\section{Tersedia Online di}

http://www.jurnal.unublitar.ac.id/i ndex.php/briliant

\section{Sejarah Artikel}

Diterima pada 27 Desember 2019

Disetujui pada 23 Januari 2020

Dipublikasikan pada 29 Februari

2020 Hal. 61-68

\section{Kata Kunci:}

Monitoring dan evaluasi;

Pemberian RPS; UTS bersama

\section{DOI:}

http://dx.doi.org/10.28926/briliant. v3i4.425

\begin{abstract}
Abstrak: Penelitian ini merupakan penelitian deskriptif kuantitatif yang bertujuan untuk mendeskripsikan upaya peningkatan akuntabilitas evaluasi kegiatan perkuliahan melalui upaya pemberian RPS perkuliahan, pelaksanaan ujian bersama dan melakukan pembahasan ujian bersama. Penelitian ini merupakan penelitian survey yang dilakukan pada seluruh dosen di Jurusan Fisika Universitas Negeri Malang dalam kegiatan monitoring dan evaluasi kegiatan perkuliahan. Berdasarkan hasil penelitian yang dilakukan, diperoleh kesimpulan bahwa (1) seluruh mata kuliah memberikan RPS diawal perkuliahan; (2) seluruh mata kuliah melakukan UTS bersama, kecuali beberapa mata kuliah praktikum, dan (3) jumlah dosen yang melakukan pembahasan hasil UTS sudah cukup banyak.
\end{abstract}

\section{PENDAHULUAN}

Pendidikan tinggi merupakan salah satu jenjang pendidikan yang ditempuh setelah pendidikan jenjang menengah. Secara khusus, pendidikan tinggi memegang peranan penting dalam menjamin tercetaknya kaum intelektual yang bermuara pada kemajuan bangsa. Secara internal, dosen-dosen dalam setiap perguruan tinggi dituntut untuk melaksanakan tridarma perguruan tinggi, yakni melaksanakan pengajaran, penelitian, dan pengabdian (Widawati dkk., 2010). Dalam pelaksanaan tuntutan tridharma serta proses mencapai tujuan Perguruan Tinggi, Universitas Negeri Malang (UM) telah berupaya untuk mengimplementasikan standar-standar pada proses perkuliahan yang memenuhi kebutuhan standar yang diterapkan oleh kampus. Upaya perancangan dan pelaksanaan standar tersebut dalam rangka menjamin mutu internal perguruan tinggi yang kemudian berdampak pada peningkatan mutu eksternal.

Dalam upaya peningkatan kualitas sistem, dilakukan melalui beberapa proses yakni proses perencanaan, penerapan, pengendalian dan pengembangan sistem manajemen mutu. Untuk dapat menjamin sistem manajemen mutu dalam perguuruan tinggi, UM mengikuti standar internasional ISO 9001:2008. ISO 
9001:2008 ini telah memiliki standar proses bagi tataran praktice sebuah organisasi.

Standar terbaru yang telah diterbitkan oleh ISO adalah ISO 9001:2015. Dengan penerbitan ISO 9001:2015 maka ISO 9001:2008 sudat tidak berlaku lagi. Oleh karenanya UM melakukan implementasi penyesuaian terhadap ISO 9001:2015. Hal tersebut sebagai salah satu wujud upaya UM dalam mejaga kualitas proses pelaksanaan kebijakan agar menjamin kualitas output yang konsisten karena adanya penerapan risk based thinking pada ISO 9001:2015 (Ibrohim, 2015). Untuk memperoleh output yang konsisten maka sebuah organisasi harus mampu menangani resiko dan peluang isu atau pengaruh yang tidak diharapkan (Puspitasari dkk., 2018). Selain itu, organisasi harus mampu pula dalam meningkatkan pengaruh yang diinginkan agar dapat menentukan tindakan yang tepat untuk mencegah serta menanganinya

Selain menerapkan pemikiran berbasis risiko, ISO 9001:2015 menerapkan pendekatan yang menggabungkan siklus proses perencanaan, penerapan, pengendalian dan pengembangan (Plan-Do-Check-Act). Siklus proses tersebut dituangkan ke dalam klausul-klausul ISO 9001:2015. Salah satu siklus tersebut adalah proses pengendalian pada klausul 9. Proses pengendalian yang sering digunakan adalah monitoring dan evaluasi. Pada penelitian kali ini, diambil kasus monitoring dan evaluasi proses perkuliahan, termasuk di dalamnya kegiatan ujian yang dilaksanakan secara serentak.

Secara jeneral evaluasi merupakan serangkaian proses terencana dalam merencanakan, mendapatkan, dan menyediakan informasi yang berguna untuk mengambil dengan yakin alternatif-alternatif keputusan (Purwanto, 2002). Evaluasi mengandung makna sebagai alat untuk guru (atau dosen) dalam menilai seberapa berhasil dan tercapai tujuan yang telah dirancang dalam proses pembelajaran atau program yang telah dilaksanakan (Mardapi, 2009). Lebih jauh (Ismail, 2013) menyatakan bahwa pada dasarnya evaluasi merupakan suatu proses dengan bermuara pada terambilnya pertimbangan atau keputusan suatu nilai yang dihasilkan dari bermacam pengamatan, latar belakang serta pelatihan dari evaluator. Berdasarkan beberapa pendapat tersebut, maka sebenarnya evaluasi dapat dimaknai sebagai kegiatan pengumpulan informasi terhadap suatu kegiatan atau program, yang mana didalamnya direncanakan tindak lanjut berdasarkan informasi yang telah terkumpul tersebut.

Untuk menjamin lulusan yang berkompeten maka kegiatan pembelajaran perlu dimonitoring dan dievaluasi. Penting untuk menjamin bahwa perkuliahan dilakukan dengan baik, menggunakan perangkat pembelajaran yang memadai, menggunakan model pembelajaran yang sesuai dan sebagainya. Selain dari sisi pembelajaran, kegiatan pengukuran ketercapaian kompetensi mata kuliah setiap mahasiswa harus seragam. Meskipun suatu mata kuliah diampu oleh dosen yang berbeda, maka pengukuran akan ketercapaian pembelajaran haruslah sama. Hal tersebut sesuai dengan tuntutan ISO 9001:2015.

Jurusan Fisika, Fakultas Matematika dan Ilmu Pengetahuan Alam telah memiliki SOP monitoring dan evaluasi proses perkuliahan yang telah dilaksanakan oleh GPM (Gugus Penjamin Mutu) yang bekerja pada level jurusan. Pelaksanaan ujian tengah semester dan akhir semester dilaksanakan secara serentak pada jurusan fisika. Penelitian ini akan difokuskan kepada upaya peningkatan akuntabilitas evaluasi kegiatan perkuliahan di Jurusan Fisika 
Universitas Negeri Malang. Hal tersebut dilakukan melalui upaya pemberian RPS perkuliahan, pelaksanaan ujian bersama dan melakukan pembahasan ujian bersama.

\section{METODE}

Penelitian ini merupakan penelitian deskriptif kuantitatif. Pengambilan data dilakukan dengan menggunakan metode survey yang dilaksanakan pada seluruh dosen dan mahasiswa jurusan fisika yang terdiri dari lima program studi, yakni S1 Pendidikan Fisika, S1 Fisika, S2 Pendidikan Fisika, S2 Fisika, dan S3 Pendidikan Fisika. Penelitian ini bertujuan untuk mendeskripsikan upaya peningkatan akuntabilitas evaluasi perkuliahan di Jurusan Fisika Universitas Negeri Malang. Upaya peningkatan akuntabilitas ini dilakukan dengan pelaksanaan ujian secara serentak dan pembahasan hasil ujian. Hal tersebut bertujuan untuk menjamin capaian kompetensi mahasiswa pada suatu mata kuliah tetap sama meskipun diajar oleh dosen berbeda. Selain itu, penelitian ini akan mendeskripsikan penyampaian RPS dosen jurusan fisika kepada mahasiswa dalam kegiatan perkuliahan.

Untuk mencapai tujuan penelitian, digunakan instrumen penelitian berupa angket. Butir-butir pernyataan pada angket dirancang untuk mengungkap tanggapan dosen terkait pelaksanaan pelaksanaan perkuliahan di jurusan fisika. Pernyataan dibuat dengan menyertakan respon dalam bentuk skala psikometrik berupa skala likert. Selain itu, beberapa butir dibuat dalam bentuk pertanyaan terbuka untuk mengungkap data yang lebih mendalam.

Analisis data dilakukan dengan menentukan persentase untuk tiap-tiap kriteria. Penentuan persentase bertujuan untuk mendeskripsikan keadaan. Data persentase untuk masing-masing kriteria ditampilkan dalam bentuk diagram untuk mempermudah interpretasi.

\section{HASIL}

\section{Pemberian Rencana Pembelajaran Semester (RPS)}

Pemberian RPS bagi mahasiswa dalam kegiatan perkuliahan merupakan hal penting. Data pemberian RPS pada perkuliahan di Jurusan Fisika.

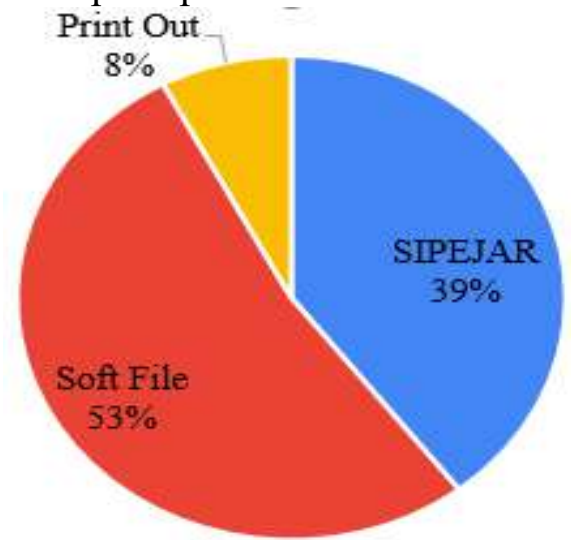

Gambar 1. Data Pemberian RPS

Pemberian RPS di jurusan fisika sudah diwajibkan. Setiap dosen harus memberikan RPS diawal perkuliahan. Permberian RPS dapat dalam beberapa bentuk, yakni (1) file yang diberikan secara langsung kepada mahasiswa, (2) print 
out, dan (3) melalui SIPEJAR (Sistem Pengelolaan Pembelajaran). Berdasarkan data yang diperoleh dari penelitian, 53\% dosen memberikan RPS dalam bentuk soft file, 39\% melalui SIPEJAR, dan $8 \%$ dalam bentuk print out.

\section{Pelaksanaan Ujian Tengah Semester (UTS) Bersama}

Ujian Tengah Semester dilaksanakan secara serentak untuk seluruh mata kuliah teori pada program studi di Jurusan Fisika. Persentase pelaksanaan UTS bersama di Jurusan Fisika seperti yang ditunjukkan Gambar 3.

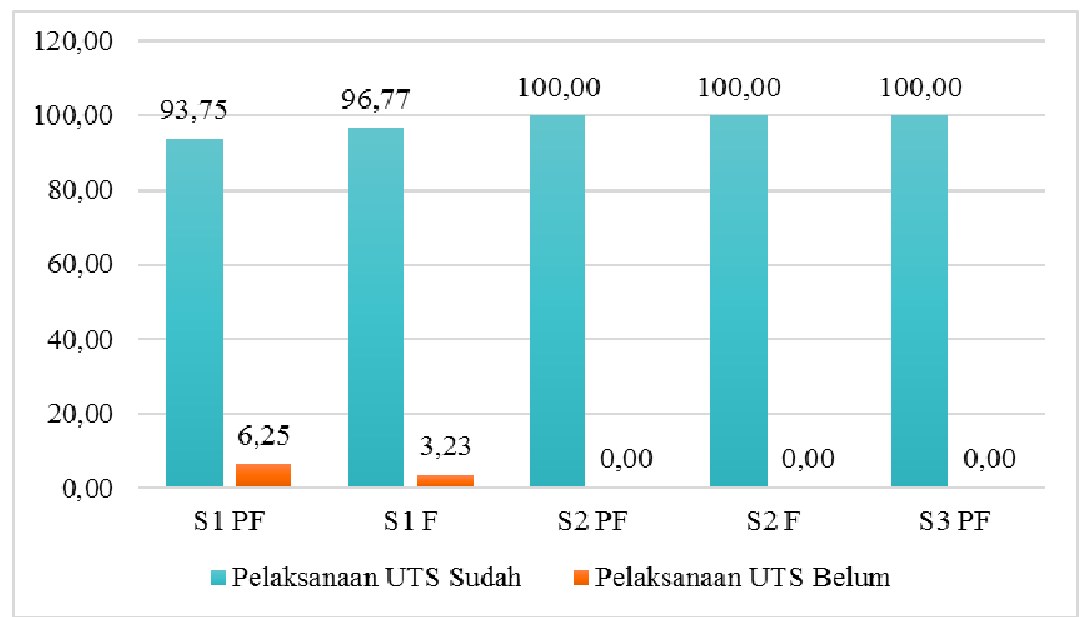

Gambar 3. Persentase Pelaksanaan Ujian Tengah Semester Tiap Mata Kuliah

Pelasanaan UTS telah dilakukan $100 \%$ secara serentak pada program studi S2 Pendidikan Fisika (S2 PF), S2 Fisika (S2 F), dan S3 Pendidikan Fisika (S3 PF). Pada program studi S1 Pendidikan Fisika (S1 PF), pelaksanaan UTS serentak baru dilaksanakan pada 93,75\% kelas. Terakhir, untuk studi S1 Fisika (S1 F), pelaksanaan UTS serentak baru dilaksanakan pada 96,77\% kelas.

\section{Pembahasan Ujian Tengah Semester (UTS)}

Setelah pelaksanaan UTS, sebagiknya soal-soal dibahas oleh tiap dosen pengampu. Hal tersebut bertujuan agar mahasiswa dapat mengetahui kekurangan dan kelebihan mereka. Data persentasi pembahasan UTS seperti yang ditunjukkan Gambar 4.

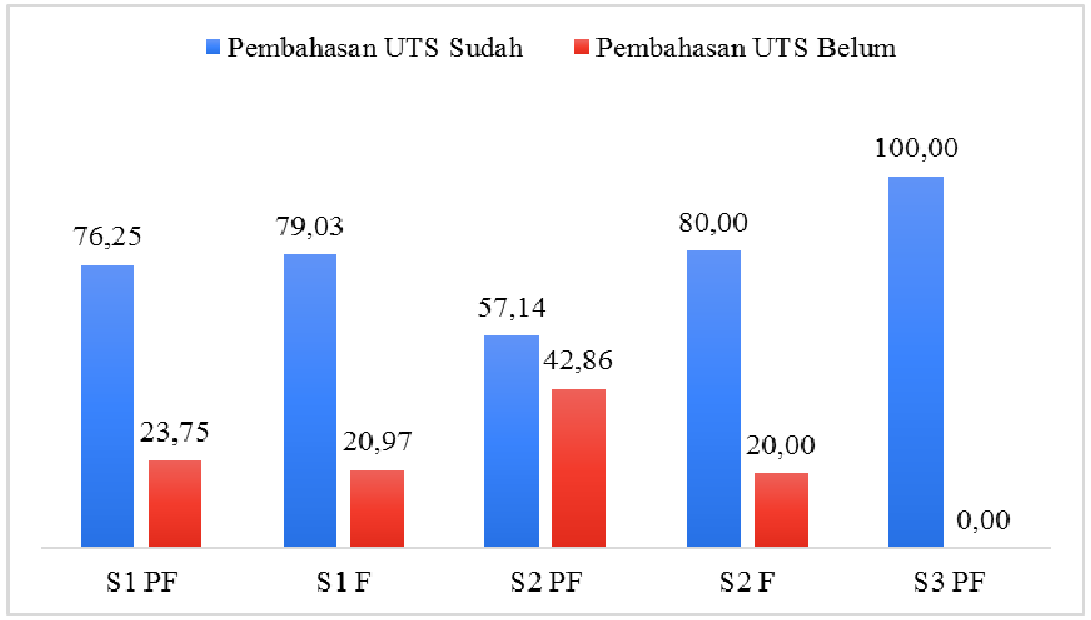

Gambar 4. Persentase Pembahasan UTS 
Berdasarkan data tersebut dapat dilihat bahwa sebagian besar dosen telah membahas ujian tengah semester di kelas. Untuk mahasiswa S1 Pendidikan Fisika, sebanyak $76,25 \%$ kelas telah membahas UTS, namun pada program studi S2 Pendidikan Fisika yang telah membahas UTS hanya 57,14\%. Pada program studi S1 Fisika, sebanyak 79,03\% kelas telah membahas UTS dan $80 \%$ untuk kelas S2 Fisika.

\section{PEMBAHASAN}

\section{Pemberian Rencana Pembelajaran Semester (RPS)}

Pada dasarnya mengajar merupakan upaya untuk membantu siswa mendapatkan informasi/pengetahuan, ide, kecakapan, nilai, maupun cara berpikir (N. Purwanto, 1996). Agar dapat mampu mencapai tujuan pembelajaran yang diharapkan, maka perlu dipilih oleh pengajar terkait metode, pendekatan, maupun model pembelajaran (Fakhrurrazi, 2018) bahkan media dan cara asesmen juga penting ditentukan dengan baik. Pemilihan, penetapan, dan pengembangan pembelajaran juga harus terencana dengan matang. Perencanaan tersebut perlu dituangkan dalam dokumen formal, yang dinamai sebagai RPS (Rencana Pembelajaran Semester).

RPS (dalam tataran sekolah dasar hingga atas adalah RPP) merupakan catatan perencanaan pembelajaran yang dirancang oleh pengajar. Berdasarkan perencanaan ini pengajar menerapkan kegiatan pembelajaran secara terstruktur di kelas. Menurut pakar pendidikan menggunakan RPS cukup efektif dalam meningkatkan kualitas mahasiswa (Setyawanto dkk., 2012). Oleh karena itu, kualitas perencanaan yang benar-benar matang menajadi salah satu aspek penting dalam pelaksanaan pembelajaran yang efektif dan efisien.

Rancangan kegiatan pembelajaran yang matang juga harus diketahui oleh peserta didik. Peserta didik akan lebih baik belajar jika mengetahui kegiatan pembelajaran yang akan mereka lakukan. Terutama untuk mahasiswa, tingkat kemandirian mereka dalam belajar sangatlah penting. Oleh karena itu, pemberian RPS pada mahasiswa menjadi hal yang perlu agar mahasiswa mengetahui apa yang harus mereka kerjakan agar berhasil mencapai tuntutan mata kuliah. Di Jurusan Fisika Universitas Negeri Malang, pemberian RPS perkuliahan kepada mahasiswa sudah 100\% dilaksanakan. Hal ini diharapkan menjadi salah satu pendukung untuk dapat menghasilkan lulusan yang sesuai dengan yang diharapkan.

\section{Pelaksanaan Ujian Tengah Semester (UTS) Bersama}

Pelaksanaan ujian merupakan salah satu cara evaluasi kegiatan perkuliahan yang telah dilaksanakan. Dari sisi pengajar, kegiatan evaluasi menghasilkan informasi sebagai sumber keputusan terkait apa yang selanjutnya akan dilakukan oleh pengajar pada kegiatan pengajaran selanjutnya (Mardapi, 2009; M. N. Purwanto, 2002). Pada dasarnya, segala keputusan yang diambil oleh pengajar harus didasarkan dari berbagai pengamatan, ragam faktor yang perlu dipertimbangkan, dan pelatihan skill dari seorang evaluator (Ismail, 2013).

Dalam kurikulum di Universitas Negeri Malang, setiap mahasiswa harus mampu mencapai CPMK (Capaian Mata Kuliah) yang telah ditentukan. Setiap mata kuliah yang sama memiliki CPMK yang sama. Oleh karena itu, mahasiswa harus diujikan dengan standar soal yang sama meskipun pada mata kuliah yang 
sama diampu oleh dosen yang berbeda. Hal tersebut bertujuan untuk memastikan bahwa seluruh mahasiswa telah mencapai kompetensi tertentu yang diukur dengan menggunakan instrumen yang sama.

Dari data yang ditunjukkan Gambar 3 tampak bahwa pada jenjang S1 masih ada mata kuliah yang tidak melakukan ujian bersama. Pada program studi S1 Pendidikan Fisika sebanyak 6,25\% kelas belum melaksanakan kegiatan ujian bersama dan S1 Fisika sebanyak 3,23\%. Keseluruhan mata kuliah yang belum melaksanakan ujian bersama adalah kelas praktikum. Kendala jika kelas praktikum melaksanakan ujian praktikum adalah keterbatasan set alat praktikum. Jika mahasiswa harus ujian serentak, maka sangat tidak dimungkinkan jika tes yang dilakukan adalah tes unjuk kinerja. Namun demikian, jurusan fisika tetap mengupayaan adanya koordinasi antar dosen pengampu mata kuliah praktikum agar ujian praktikum tetap menguji aspek yang sama.

\section{Pembahasan Ujian Tengah Semester (UTS)}

Pembahasan UTS di kelas bertujuan untuk memberikan feedback kepada mahasiswa. Kebergunaan feedback dalam kegiatan penilaian memegang peranan penting dalam pencapaian tujuan pembelajaran (Afwa dkk., 2016; Sutopo dkk., 2016; Suweken, 2014; Muhammad Reyza Arief Taqwa, 2016). Bahkan di dalam pembelajaran, kesegeraan feedback ini menjadi hal yang utama (Muhammad Reyza Arief Taqwa dkk., 2017, 2016; Muhammad Reyza Arief Taqwa \& Faizah, 2016). Bahkan tidak hanya untuk pelajar, kebergunaan feedback juga penting untuk mengevaluasi keberhasilan pembelajaran yang telah dilaksanakan. Feedback berguna untuk menilai kinerja guru dalam menciptakan suasana pembelajaran yang baik (Yu, 2016). Selain itu, untuk melatih kemampuan penting yakni pemecahan masalah (Taqwa dkk., 2019).

Perkuliahan di Jurusan Fisika telah memfasilitasi mahasiswa untuk memperoleh feedback setelah kegiatan ujian. Siswa harus mengetahui kekurangan dan kelebihan yang mereka miliki. Dalam fisika (atau mungkin pembelajaran lain), jika ujian tidak disertai dengan pemberian feedback dengan segera maka justru akan berbahaya bagi mahasiswa. Hal tersebut terjadi jika mahasiswa memiliki pemahaman yang keliru, namun kekeliruan konsep tersebut tidak segera diberikan feedback maka akan semakin retensi bagi pelaksanaan pembelajaran kedepannya. Oleh karena itu, dosen di Jurusan Fisika dihimbau untuk memberikan pembahasan UTS kepada mahasiswa meskipun belum seluruhnya dikarenakan kendala keterbatasan waktu.

\section{KESIMPULAN}

Pemberian RPS pada perkuliahan diberikan dengan 53\% dosen memberikan RPS dalam bentuk soft file, 39\% melalui SIPEJAR, dan $8 \%$ dalam bentuk print out. Hal tersebut menunjukkan bahwa seluruh dosen telah memberikan RPS untuk semua mata kuliah. Untuk kegiatan ujian tengah semester bersama, dilaksanakan oleh $93,75 \%$ kelas pada program studi S1 Pendidikan Fisika dan 96,77\% kelas pada program studi S1 Fisika, sedangkan kelas pada program studi S2 Pendidikan Fisika, S2 Fisika dan S3 Pendidikan Fisika telah $100 \%$ kelas telah melakukan ujian tengah semester bersama. Secara umum hampir seluruh mata kuliah teori telah melakukan kegiatan UTS bersama, hanya beberapa mata kuliah praktikum yang belum melakukan kegiatan UTS bersama. Terakhir, 
persentase kelas yang membahas hasil ujian tengah semester adalah 76,25\% untuk S1 Pendidikan Fisika, 79,03\% untuk S1 Fisika, 57,14\% untuk S2 Pendidikan Fisika, 80\% untuk S2 Fisika, dan 100\% untuk S3 Pendidikan Fisika. Hal tersebut menunjukkan bahwa jumlah dosen yang melakukan pembahasan hasil UTS sudah cukup banyak.

\section{SARAN}

Berdasarkan paparan hasil penelitian, diharapkan dapat menjadi bahan pertimbangan bagi institusi untuk melakukan kegiatan serupa bahkan sebisa mungkin lebih baik dari yang telah dilakukan oleh Jurusan Fisika Universitas Negeri Malang. Namun penelitian ini masih terbatas responden dosen. Penelitian terkait monitoring dan evaluasi perkuliahan dapat diperdalam dengan menggali data lebih mendalam berdasarkan perspektif mahasiswa untuk kedepannya.

\section{DAFTAR RUJUKAN}

Afwa, I. L., Sutopo, \& Latifah, E. (2016). Deep learning question untuk meningkatkan pemahaman konsep fisika. Jurnal Pendidikan: Teori, Penelitian, dan Pengembangan, 1(3), 434-447.

Fakhrurrazi, O.: (2018). Hakikat pembelajaran yang efektif. Dalam Jurnal AtTafkir: Vol. XI (Nomor 1).

Ibrohim, L. (2015). ISO-9001: 2015 FDIS, Penjelasan Klausul-Klausul. PT. Gunastara.

Ismail, F. (2013). Inovasi Evaluasi Hasil Belajar Pendidikan Agama Islam (Model-Model Penilaian Berbasis Afektif). Jurnal Ta'dib, 18(02), 228259.

Mardapi, D. (2009). Evaluasi penerapan ujian akhir Sekolah Dasar berbasis standar nasional. Jurnal Penelitian Dan Evaluasi Pendidikan, 13(2), 227245.

Purwanto, M. N. (2002). Prinsip-Prinsip Evaluasi Pengajaran. Rosda Karya.

Purwanto, N. (1996). Psikologi Pendidikan. Rosda Karya.

Puspitasari, A. K., Widaningrum, S., \& Lalu, H. (2018). Perancangan Sop Monitoring Dan Evaluasi Perkuliahan Sesuai Iso 9001: 2015 (Klausul 9.1. 1 Dan 9.1. 3) Dengan Mempertimbangkan Risiko Di Universitas Telkom. Journal Industrial Servicess, 3(2).

Setyawanto, A., Hs, S., \& Agus Basuki, I. (2012). Rencana Pelaksanaan Pembelajaran (RPP) Guru Bahasa Indonesia Tingkat SMP Di Kota Malang.

Sutopo, Jayanti, I. B., \& Wartono. (2016). Efektivitas program resitasi berbasis komputer untuk meningkatkan penguasaan konsep mahasiswa tentang gaya dan gerak. Jurnal Inovasi dan Pembelajaran Fisika, 3(1), 111-119.

Suweken, G. (2014). Asesmen online untuk meningkatkan keterlibatan dan kualitas pembelajaran matematika. Dalam Seminar Nasional FMIPA UNDIKSHA IV Tahun.

Taqwa, M. R. A., Faizah, R., Rivaldo, L., Safitri, D. E., Aini, F. N., \& Sodiqin, M. I. (2019). Students' Problem-Solving Ability in Temperature and Heat Concepts. Journal of Physics: Conference Series, 1339, 012132. 
Taqwa, Muhammad Reyza Arief. (2016). Perlunya Program Resitasi untuk Meningkatkan Kemampuan Mahasiswa dalam Memahami Konsep Gaya dan Gerak. Pros. Semnas Pend. IPA Pascasarjana UM, 1, 365-372.

Taqwa, Muhammad Reyza Arief, \& Faizah, R. (2016). Perlunya Program Resitasi untuk Meningkatkan Kemampuan Mahasiswa dalam Memahami Konsep Gaya dan Gerak. Pros. Semnas Pend. IPA Pascasarjana UM, 12(1), 365372.

Taqwa, Muhammad Reyza Arief, Hidayat, A., \& Sutopo. (2017). Deskripsi Penggunaan Program Resitasi dalam Meningkatkan Kemampuan Membangun Free-Body Diagrams ( FBDs ). Jurnal Pendidikan Fisika Tadulako, 5(1), 52-58. https://doi.org/10.22487/j25805924.2017.v5.i1.8411

Taqwa, Muhammad Reyza Arief, Hidayat, A., \& Sutopo. (2016). Recitation Program Based On Multi Representation Needed to Increasing the Kinematics Conceptual Understading. The 2nd International Seminar on Science Education (ISSE) Graduate School-Yogyakarta State University, 60-66.

Widawati, L., Styani, Y., \& Nadya, D. (2010). Profil Komitmen Dosen dalam Kegiatan Tridarma Perguruan Tinggi. MIMBAR: Jurnal Sosial dan Pembangunan, 26(1), 93-104.

$\mathrm{Yu}, \mathrm{O}$. S. (2016). Using students' feedback to evaluate teachers' effectiveness. Journal for Educators, Teachers and Trainers JETT, 7(1), 182-192. 